\title{
O ESQUECIMENTO DIZ RESPEITO AO MELHOR: PLURILINGUISMO E ERRÂNCIA NOS POEMAS DE MOACIR AMÂNCIO
}

MÁrcio SELIGMANN-SILVA*

\section{RESUMo}

O texto discute o volume Matula, de Moacir Amâncio. Aí o poeta recolheu os fragmentos da judeidade ibérica e de seus desdobramentos em Amsterdã, no Recife e pelo mundo afora. O artigo mostra como nesse livro tudo agora se transforma em traço de memória. Essas marcas são revalorizadas e constituem uma obra que além de memorial é profundamente irônica, pois recicla de modo livre, aberto e muitas vezes divertido, séculos de histórias e narrativas. O universo plurilíngue de Amâncio, que escreve também em hebraico, espanhol, inglês e esbarra no ladino, língua da judeidade sefardita, corresponde ao périplo da dispersão dos judeus, perseguidos pela Inquisição e sempre tentando sobreviver em outras terras. A diáspora figura aí como uma sequência de novos encontros e de desencontros.

PALAVRAS-CHAVE: cultura sefardita; errância; diáspora; poesia plurilíngue.

"o que sopra dos abismos do esquecimento é uma tempestade" Walter Benjamin, 1934 (2012, p. 176)

Como dar forma ao esquecido? É fácil associarmos, e isso tem sido feito desde a Antiguidade, a poesia à arte da memória. Mas desde a Modernidade impõe-se outra questão: É possível fazer poesia e literatura a partir do esquecimento? Walter Benjamin dizia que o esquecido é um dos protagonistas da obra de Kafka, essa verdadeira pérola da literatura moderna. Segundo o filósofo, num pensamento, de resto, bem ao gosto de Freud, não é porque algo é esquecido que ele não se manifestaria no

Professor titular da Universidade Estadual de Campinas/ UNICAMP, Campinas, São Paulo, Brasil.

E-mail: marcioseligmann@icloud.com 
presente, pelo contrário: "é esse esquecimento que o torna presente". (2012, p. 168). Mesmo porque trata-se em Kafka de um esquecimento coletivo: "o esquecimento [...] não é nunca um esquecimento meramente individual”, enfatiza Benjamin (2012, p. 169) Isso ele escreveu em um artigo de 1934 por ocasião dos 10 anos da morte do escritor de Praga. Já em 1938, em uma longa carta a seu amigo Gershom Scholem, ele afirma que "a obra de Kafka representa um adoecimento da tradição". (1993, p. 303). Kafka enfatizaria a transmissibilidade, mas o conteúdo mesmo, a lei, a tradição, estaria como que esquecida na sua obra.

Iniciei este texto com essa referência à leitura benjaminiana de Kafka porque tratarei aqui de um escritor paulista, Moacir Amâncio, nascido em 1949, mais especificamente de seus poemas, nos quais percebemos também essa construção poética em torno do esquecimento. Trata-se de uma obra que ronda um vazio pleno de sentido, que imanta o presente e as palavras, transformando-as em um recipiente que permite vislumbrar esse mesmo vazio. Não por acaso, portanto, o último livro de Amâncio, sobre o qual me debruçarei aqui, se chama Matula (2016). Segundo o Dicionário Houaiss, matula significa tanto "ajuntamento de gente ordinária; corja, súcia, matulagem”, significados que logo nos interessarão, como também "alforje, farnel” e ainda, no parônimo mátula, "vaso, gamela”, tendo também sinonímia com penico. Seria um termo derivado de "matalotagem (no sentido de 'provisão') ”. Esse sentido de “"vaso ou vasilha para líquidos”, ainda segundo o Houaiss, permite-nos reconhecer nessa obra de Amâncio um tal vaso que contém esse vazio de um esquecimento tão prenhe de significados. Mas a poética do escritor e professor de literatura hebraica não é a mesma do autor de A metamorfose. Ao invés de mostrar emaranhado ao esquecido elementos primevos de nossa constituição, ele constrói uma intrigante e até certo ponto lúdica poética do esquecimento. Esse jogo poético consiste em salpicar em todo canto a hermenêutica da suspeita. Amâncio em alguns de seus poemas anteriores e em todos os de Matula brinca de esconde-esconde com a tradição para revelá-la. Em uma poética que também lembra Kafka por seus traços de escrita de si, ele se apresenta como parte de uma linhagem 
de herdeiros do esquecimento. De que esquecimento se trata? Antes de mais nada da origem, ou, como escreveu Benjamin, da tradição. Essa tradição é, fica evidente, a tradição judaica sufocada desde a Inquisição ibérica. Dentro dessa tradição da cultura marrana, ou seja, no mundo do ben anussim, ou do filho de forçados, em hebraico, estabelece-se uma tensão sem solução entre o recordar e o esquecer. Essa é a pedra de toque dessa tradição da morte da tradição e o seu encanto. No contexto da Inquisição, por séculos impuseram-se práticas de escamoteamento da judeidade. E justamente nesse contexto, gestos eram mantidos como autoafirmação de uma origem cortada, tornada pecado e suja. Como escreve Amâncio em um poema curto de Matula: "cripto tão críptico/ que se ignora/ porém guarda”. Temos aqui quase uma metáfora do trauma do ponto de vista psicanalítico e, não por acaso, os discípulos de Freud, Nicholas Abraham e Maria Torok reinterpretaram o trauma do ponto de vista de uma teoria da cripta e do encriptamento de lembranças fantasmáticas. Os gestos judaizantes, como sintomas do passado recalcado, estavam fadados ao desvio e ao travestimento: sugere-se escondendo, esconde-se sugerindo. Séculos de tradição dessa antitradição determinaram um estilo único, que guarda desde sempre um parentesco com a ironia moderna (moderna já em Cervantes) e que determina o jogo poético reciclado por novos autores marranos atuais, dentre os quais se encontra o nosso protagonista. O termo marrano, como matula, lembra o Houaiss, traz em si a marca da perseguição e derrisão: significa tanto judeu ou mouro batizado, como excomungado, mas também gado ruim, imundice, sujeira. Sua etimologia deriva de porco, do árabe: muharram, coisa proibida, ou seja, carne de porco. O termo "judiar", como Amâncio recorda citando outro dicionarista, Aurélio, também é um traço, um memento da violência contra uma etnia conservado na língua portuguesa de modo cristalino: "judiar: [...] tratar como antigamente se tratavam os judeus escarnecer maltratar escarnecer, mofar, zombar, judiar com alguém fazer judiaria fazer sofrer atormentar maltratar judiar dos animais aurélio”. Hoje, no entanto, o jogo poético com essa tradição é totalmente resignificado, retraduzido sem perder suas características antigas. Encontramos a tensão entre o dizer 
e o desdizer, a fragmentação, o jogo com onomásticos e toponímicos, a ironia, o anedotário, referências bíblicas e propensão mística, além de outras tantas características, mas acrescidas agora de um novo desejo de etnogênese, marca de nossa contemporaneidade. Amâncio constrói a sua Eretz Israel reconstruindo uma descendência em parte imaginária, marcada ao mesmo tempo pela piedade, pelas fugas e perseguições, mas também pela criatividade e capacidade inventiva de se disfarçar. Isso tudo curtido em altas doses de esquecimento e recordação. Trata-se de lembrar do esquecido, mas de um esquecido essencial, que tem seu valor derivado do fato de nunca poder existir integralmente. Tornou-se, portanto, matéria fértil para a poesia e é disso que Amâncio sabe se aproveitar muito bem. Ele coleta os vestígios dessa tradição do naufrágio.

Matula tem em sua capa uma bela Fênix-tatuagem que faz as vezes de uma guardiã protetora. Ela protege essa obra que é na verdade essa ambígua arca da memória do esquecimento. Amâncio recolheu nela os fragmentos da judeidade portuguesa-espanhola e de seus desdobramentos em Amsterdã, no Recife e pelo mundo afora. A Fênix é o pássaro que se renova e renasce a cada ciclo, como os judeus em sua dispersão. Esse pássaro também estava estampado na capa da talvez primeira obra de autor marrano publicada em solo brasileiro, ainda no século XVI, a Prosopopeia, de Bento Teixeira Pinto (1561-1600), conforme indica o próprio Amâncio em palestra proferida em torno do marranismo e de seu Matula. Ele nota também que esse mesmo pássaro imortal é o símbolo da comunidade Nevê Shalom dos judeus portugueses de Amsterdã.

O livro (i)memorial se abre paradoxalmente com um anexo de Luís Nunes Tinoco (1642-1719), um poeta, pintor e calígrafo português, autor de A Feniz (sic) de Portugal Prodigiosa, com anagramas que ofereceu à rainha Maria Sofia Isabel. Tudo no livro de Amâncio lembra essa metáfora da arca-arquivo: que salva escombros que são citados, comentados ou parafraseados. É como se o mundo se desfizesse em letras. E o próprio Luís Nunes Tinoco, na apresentação do referido texto, deixava claro a visão de mundo mística judaica que se conserva no poeta paulista. Tinoco lavrou: 
He o mundo todo hum grande livro de que emana a Sciencia da Orthographia: cujos Tratados são as Idades, os Capítulos, os Séulos, as folhas os annos, os paragrafos os mezes, as Regras os Dias e as Letras as Horas. [...] Foy Adam a primeira Letra do Alfabeto Racional que Deus tirou e criou do Nada, que hé Anagramma de Adam na língua espanhola [...] Com Estrellas de brilhante ouro escreveu Deus as Letras redondas sobre o azul dos Celestes Orbes: com flores de varias cores formou Alfabetos de diferentes matizes na Terra: com aves de diversas formas delineou vistozas penadas no Ar. Nesta cristalina lamina desse humido Elemento abriu o subtil buril da Divina Providencia Letras de prata que posto sejam só Mutas, e Líquidas não deixam de se soletrar nellas innumeraveis maravilhas da Natureza, que se lêm como Agua. [...] Finalmente nesta Machína do Orbe todas as criaturas são A B C de Deos, como diz Santo Ambrosio, por onde cada natureza he huma letra cada vínculo huma sylaba e cada geração muytas dicções: não havendo criatura alguma por pequena que seja que não sirva de folha no volume do Mundo." (1678 apud HARTHELY, 1999, on-line.)

É digno de nota que esse tipo de visão escritural do mundo, como também o demonstrou Benjamin em seu livro sobre o Trauerspiel, é típico do Barroco e de sua alegorese. Um mundo esvaziado de transcendência é ressignificado ludicamente pelo poeta barroco com seus constructos enigmáticos, como no caso dos emblemas. Neles coexistem palavras e imagens que se tensionam e alimentam mutuamente produzindo interpretações das mais variadas, que projetam um mundo místico onde muitas vezes tem-se na verdade um vazio. Sem dúvidas, também Amâncio é tributário desse jogo barroco, como vemos, por exemplo, em seus inúmeros poemas-nomes. Neles a tendência barroca para aquilo que Benjamin chamou de "armazenamento" (Magazinierung) é levada a sua última consequência:

O ideal de saber do barroco, o armazenamento [Magazinierung], cujo monumento se cristalizou nas bibliotecas gigantes, é realizado pela imagem escrita [Schriftbild]. Quase como na China, é como se uma tal imagem fosse não signo do que deve ser sabido, mas, antes, um objeto em si mesmo digno de ser conhecido. (BENJAMIN, 1980, p. 359). 
E Amâncio compõe seu universo gramatológico-onomástico listando nomes em um verdadeiro arquivo da sobrevivência onde o $\mathrm{Eu}$ (poético, mas não só este) se reinventa:

tu não és

quem pensas que és

(pergunta pelo primo dirigida a E.M.M.C.)

p.s.

etc. os câmara zarco ferreira melo rosa peixoto mesquita pinto mendes preto magriço corte real bezerra cardozo frances moreno rodrigues soares bentes rozales rodrigues mendes roiz pereira carranca sequerra silva zacuto câmara zarco ferreira melo rosa ferreira peixoto mesquita pinto mendes preto magriço corte real bezerra cardozo frances moreno rodrigues soares bentes rozales rodrigues mendes roiz souza pereira carranca brito sequerra silva zacuto câmara zarco ferreira melo rosa peixoto mesquita pinto mendes preto magriço corte real campos cardozo frances moreno rodrigues soares bentes rozales rodrigues mendes roiz pereira carranca sequerra silva zacuto câmara zarco ferreira melo rosa peixoto pinto mendes preto souza brito magriço barbosa roiz sá campos cardozo frances moreno soares bentes rozales mendes roiz pereira carranca sequerra silva zacuto câmara zarco ferreira melo e castro rosa peixoto mesquita pinto mendes preto magriço corte real campos cardozo frances moreno rodrigues maia bentes rozales rodrigues mendes rosa pereira carranca sequerra monsanto chaves belmonte etc.

Nesses nomes sobrevivem os filhos e descendentes dos forçados à conversão e esquecimento, como que em uma desforra da história de violências. Se o mundo se dispersa em palavras, como um livro aberto cujas folhas se espalharam, as letras que compõem os nomes lhe dão um lastro. O nome é o intraduzível por excelência. É o nervo duro da linguagem. Segundo a cabala, criada e seguida por muitos dos autores recordados por Amâncio, a língua originária foi a língua de Adão, uma língua de nomes que ele deu a cada ser, lendo a criptoescrita que Deus deixara em suas criaturas. Nomes são fragmentos robustos do passado. Nomes tornam- 
se as palavras-chave do poema do mundo da dispersão: são nossas casas, arruinadas, mas nas quais encontramos abrigo. Construídas com a consciência de que o passado nunca pode ser restaurado. Como diz o poeta Amâncio: "ninguém pode ir pra casa de novo/ só como estrangeiro/ todos nós”.

Amâncio é o catador das palavras e imagens que ele reorganiza nesse livro-montagem, um verdadeiro painel da judeidade e da criptojudeidade marrana. Tudo se mistura aqui, inclusive o mais privado e o mais histórico: "marrano de pai mãe e avós eu o sou", lemos em um verso. E mais: "foi esta a equação/ tetratetravós judeus/ tetravós marranos/ bisneto ateu”. A história é apresentada como um quiasmo: é um processo de afastamento da tradição, mas também, o presente é visto como um local de encontro com os escombros do passado. Tudo agora se transforma em traço de memória nessa poética lúdica que tinge tudo com o tom da alusão e da sobrevivência. O leitor se transforma em detetive dessa história da tentativa de apagamento de uma tradição e da resistência a esse apagamento. Outro poema: "eu sou o único judeu na minha família/ toda hoje/venho do ramo de samuel usque": judeu lisboeta autor de "Consolação às tribulações de Israel” (1553). Esses judeus, como a família de Espinosa (muito presente no livro, aliás) tiveram que enfrentar "seja amsterdã quem sabe hamburgo ou mesmo o bósforo/ ainda recife pode ser constantinopla/ onde seremos por demais talvez em rhodes/ faremos lá a nossa língua”. E essas línguas não pararam de ser criadas, como neste belo livro-arca de Amâncio que em sua paixão pelos nomes, sua atração infinita pelas estórias, cria um mundo gramatológico original, pavimentando o que chama de "o mar um ladrilho logos”. Até os cristãos novos eminentes Raposo Tavares (autor de "façanhas assassinas") e Tiradentes têm lugar nesse (anti)panteão do desterro, desespero e da recriação: Fênix.

Mas o tom geral é profundamente irônico, pois recicla de modo livre, aberto e muitas vezes divertido, séculos de histórias e narrativas. A polifonia se alia a esse traço irônico para se aproximar de noções caras a Bakhtin, como o carnavalesco. $\mathrm{O}$ universo plurilíngue de Amâncio, que escreve também em hebraico, espanhol, inglês e esbarra no ladino, língua 
da judeidade sefardita, corresponde na verdade ao périplo da dispersão dos judeus, perseguidos pela Inquisição e sempre tentando sobreviver em outras terras e línguas. A diáspora é uma sequência de novos encontros e de desencontros.

Matula está cheio também de descrições de rituais e de gestos da tradição judaica, sobretudo no que diz respeito ao culto aos mortos: lavar o corpo, colocar a mortalha, cobrir os espelhos, cortar um pedaço da roupa, não se barbear por uma semana: "respeita todo aquele que tiver a barba crescida pois/ está de luto”. Lembra também o banho sabático, varrer a sujeira para dentro, a faxina do sexto dia, "o abate dessangrento" etc. Esses hábitos sobrevivem entre os convertidos muitas vezes como memória inconsciente de um passado que Amâncio ilumina de modo sútil e até mesmo carinhoso.

As línguas se misturam assim como as vozes de autores que ele cita ou traduz em uma "plagiotropia" (termo de Haroldo de Campos, 1981, p. 75) vertiginosa. Ironicamente, em um jogo que pode nos lembrar do famoso Chansons de Billiti de Pierre Louÿs, ele introduz notas e bibliografia em seu livro de poemas, misturando o gênero acadêmico com o poético. $\mathrm{O}$ texto contém essa teoria da escrita e do mundo como infinitas reescrituras:

teria platão reescrito sócrates

teriam os evangelistas reescrito a bíblia e ieshu

teria moisés reescrito

teria espinosa

E Amâncio ecoa ou saqueia Mallarmé plantando em seu livro os versos:

se o dado foi tão desfeito só nos resta o acaso o jogo

em que todos são jogados

O ato de nomear antepassados e construir tradições e descendências é ao mesmo tempo instauração de um local, de uma "casa”, e ato reverencial. Na tradição dos livros de memória judaicos, faz-se um jazigo de palavras 
para os que sofreram perseguições. Como o autor escreve em versos: "a costureira de mortalhas/ descobre no passado claro - a tecer no passado claro/ o obscurecimento do presente. "Assim, também, um pequeno poema homenageia Antonio Enríquez Gómez, dramaturgo e poeta espanhol, nascido em 1601 em Cuenca e falecido em 1663. Criptojudeu sefardita, teve o avô marrano queimado pela Inquisição.

de la estrella de Venus tan ajeno
Antonio Enríquez Gómez

na ibéria as chamas

cresciam das masmorras

com lenha local

e dos aquém mares

onde dispersava

se em relva sem nome

Assim como o barroco Luís Nunes Tinoco, Amâncio também faz poesia imagética como em um poema em forma de X ou de taça, ou seja, de recipiente, matula, conforme o leitor preferir:

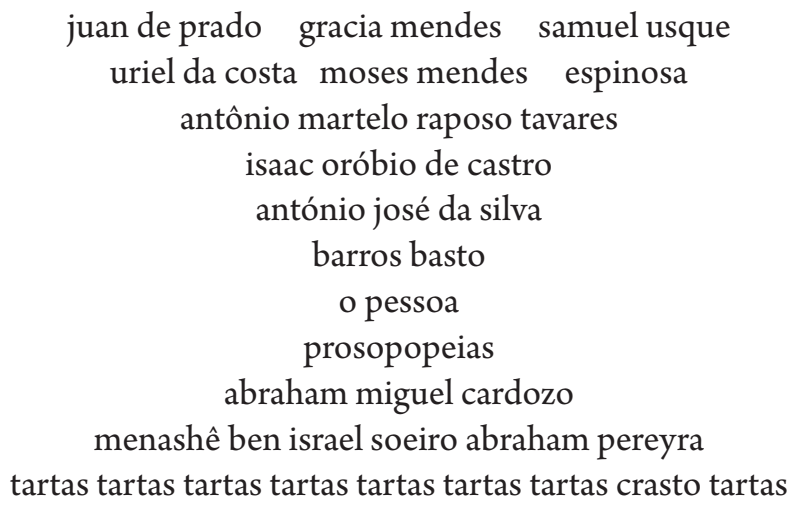

menashê ben israel soeiro abraham pereyra

tartas tartas tartas tartas tartas tartas tartas crasto tartas

David ben Abraham de Castro Tartas (1630-1698) foi um impressor de Amsterdã que publicou a Gazeta de Amsterdã, o jornal da comunidade judaica. Ele era filho de um cristão novo fugido de Bragança. 
Abraham Miguel Cardozo (1626-1706) era descendente de marranos, foi médico, cabalista e um profeta na linha de Sabbatai Zevi. Esse poema e o livro estão mesmo cheios de prosopopeias (o mencionado título do livro de Bento Teixeira Pinto), de jogos de máscaras, de inseminação de vida em seres mortos. De resto, o próprio Sabbatai Zevi aparece na pena de Amâncio como uma figura quase paradigmática das metamorfoses identitárias e mnemônicas que esse livro testemunha. Afinal, esse judeu otomano, fundador de uma poderosa seita mística inspirada na cabala, acabou se convertendo ao islamismo. Em sua lembrança escreve o poeta:

shabtai tsvi o judeu o rabino o messias o com a redenção no bolso esquerdo e todas as heresias no bolso direito o novo muçulmano convertido sob ameaça de morte para assim disse seguir no caminho da redenção sob o entulho de todas as humilhações era o judeu muçulmano e o muçulmano judeu que o messias se coloca múltiplo marrano e a farsa multiplicidade

dos brilhos de um astro

a cair a subir para o fundo

ou rumo à flor em águas do universo

e perguntam que flor é essa de setenta

e sete nomes

e tantas vezes sete a cifra inumerável

Gershom Scholem (1976, p. 441), em seu livro sobre o místico otomano, mostrou como para Sabbatai o número sete continha todo o mistério do mundo de forma concentrada. Mas Amâncio se apropria desse nome para fazê-lo renascer no misticismo político português: "sebastião/ shabtai:sabtai/?" E não sem ironia arremata: "o passado nos atualiza".

Dentro dessa poética "nominalista" Amâncio recorda também um tradutor e ator, ou seja, um especialista em representação como dissimulação, chamado Vitali Háim Ferera, cujo nome leva o poeta a um encadeamento que o ecoa e desdobra em outros nomes da tradição marrana desvendando a tradução como uma ação que acentua o nomadismo cultural marrano: 
vitali vitale vidal háim herrera

ferera de repente perera

pereira ferreira

do fausto dos dons manuéis

moedas falsas

nas mãos dos ministros ancestrais

[...] a gente da nação e a gente da nação

todos os idiomas

quando traduzes do iídiche ao espanholit

a navegar pelo bósforo entre Istambul

e jerusalém

$[\ldots]$

A "falsa moeda", como no poema em prosa de Baudelaire com esse nome, pode ser também um codinome das palavras e sobretudo da palavra poética e tradutória, com seu valor à deriva e a busca de um porto de significação sempre precário. No poema $A B$ ETERNO ele na verdade transcreve uma passagem do tratado cabalista neoplatônico Puerta del Cielo, de Abraham Cohen Herrera (1570-1635), um marrano nascido provavelmente em Lisboa que viveu em Amsterdã. Amâncio picota a prosa mística de Herrera em versos como um verdadeiro "Pierre Menard, autor del Quijote" borgeano. Amâncio ao "repetir" Cohen Herrera com quatro séculos de decalagem o ressignifica e refunda suas ideias. Ou, por outra, esse gesto de copista que traduz um tratado em poema ecoa também um gesto semelhante do grande poeta e tradutor Haroldo de Campos que publicou uma tradução em versos de uma passagem da Fenomenologia do Espírito de Hegel. ("Hegel Poeta”)

O ser nômade da cultura iluminada do ponto de vista do marranismo é explicitado ironicamente no poema em inglês "ETYMOLOGY": 
change $\mathrm{j}$ for $\mathrm{x}$ and read that letter like a gallego

or a brazilian or a portuguese

or maybe an old spanish reader

sh

in order to understand that spanish word

you might read it in hebrew

in doing so you'll get the full meaning of it

qishot or qishut

in aramaic we have qushta

truth

qishet

in hebrew

it means to make true

$[\ldots]$

Não podemos deixar de comentar o contexto da obra poética de Amâncio que desde seu Do objeto útil ([1992] 2007, p. 25-92) vem refletindo sobre alguns dos temas que são desenvolvidos de modo quase que paroxístico em Matula. Por exemplo, os temas da cópia, reprodução e tradução. Se em Matula temos a impressão que "tudo é tradução", o primeiro poema do livro de 1992, "O olho" afirma o oposto: "não se reproduz/ não se repete” (2007, p. 27). Esse elemento irreprodutível, no entanto, é parte da multiplicação de textos e de "máscaras" do autor que se desdobra para traduzir o intraduzível: da existência e da poesia. Assim, em outro poema do mesmo volume, o poeta escreve: "eu me reparto: todos os possíveis/ ainda que a máscara seja uma e só./ [...] Aqui nada matura nem conclui,/ ninguém informa sobre permanência,/ um saldo de memória ou existência.” (2007, p. 49). Aqui podemos entender como Amâncio cria com um jogo de máscara(s), literalmente, uma prosopopeia, um teatro da memória, uma mise en action dos mortos. Explico-me. Primeiro entendamos porque de certo modo o poeta representa nesse teatro nada menos do que o papel de Perséfone. O nome 
de Perséfone é derivado por alguns autores de pherein phonon, "trazer" ou "causar a morte". Mas existe outra aproximação semântica possível, particularmente importante para nos aproximarmos dessas obras de Amâncio: em etrusco, phersu significa a pessoa que porta uma máscara (originalmente em rituais fúnebres). Daí vem o termo latino persona, ou seja, o personagem dramático com sua máscara. Perséfone, via phersu, também tem sido aproximada de persona. Ela é ora caracterizada por sua extrema e irresistível beleza, ora como terrível, pavorosa (epainé). Como esposa de Hades, ela é a temida rainha do mundo dos mortos. Além disso, afirma-se que Perséfone é a mãe das temíveis Eríneas, as deusas que perseguem os assassinos para cobrar a "dívida de sangue". Elas são a memória do mal e a justiça. A relação tensa de Perséfone com a beleza e com a morte, seu natural "jogo de máscaras", sua vida que alterna entre o Hades e a primavera na terra, tudo isto faz desta figura mítica uma das mais potentes metáforas para expressar os jogos de máscara da própria literatura e das artes, que Amâncio representa de modo exemplar. Lembrando que em grego prosopon é face e máscara, podemos dizer que a literatura e as artes são também máscaras da morte: prosopopeia, personificação do "indizível", onde um personagem (ou alguém em vista já da sua morte) é vivificado como uma pessoa real.

Dentre os jogos de preferência de Amâncio em sua poética de máscara(s) encontramos seu plurilinguismo. Ele possui todo um volume de poesias em espanhol, Colores siguientes ([1999] 2007, p. 208256) e outro em língua inglesa, At (2007, p. 431-75). Em Contar a Romã ([2001] 2007, p. 257-337) Amâncio, em um longo poema, "O palácio da fronteira (ou golpes de vista)", faz uma "anotação para uma hipótese de mapa” (2007, p. 289) que já introduz seu gosto pela pesquisa histórica com destaque para o tema dos cristãos novos. A "polifonia" (2007, p. 313) é explicita nesse livro. É como se diante da intraduzibilidade e da necessidade da tradução houvesse a passagem para a polifonia: a coleção de vozes, mesmo que fictícias ou reinventadas. Como o artista 
com a sua natureza morta, que pinta cada fruto ou cebola como únicas e inimitáveis. Assim lemos em um poema de At:

This onion
is quite different
from all those on the table.

Think of each

onion

as a collection

of tongues.

Each one

over and under

another one

in an almost liquid

agreement

to make a fruit -

each one proving

the exclusive

position

of uniqueness

to produce

this phrase

as an example of

the impossibility

to translate it

into frozen solid marble,

into hot air,

into an Orange.

Each onion

Cannot be translated

Even into the same

onion. (AMÂNCIO, 2007, p. 435) 
Esse acordo que faz a fruta pode ser lido também como uma filosofia da linguagem que vê cada língua como uma perspectiva, uma fração da verdade da "cebola" indizível em uma só língua, filosofia essa que encontramos em um belo e enigmático texto de Walter Benjamin, Sobre a linguagem em geral e sobre a linguagem dos homens, de 1916. Nesse texto, Benjamin partia de uma reflexão sobre a língua pura originária, a língua do Paraíso, que teria sido repartida nos cacos que constituem as línguas individuais, desde a Queda. De resto, Amâncio vincula-se explicitamente à essa tradição judaica teológico-mística da linguagem ao conectar em seu At os quatro níveis de leitura da Tora a uma busca dessa língua paradisíaca: "the original language does exist somewhere beyond the spud (pardes [sic], meaning the four ways to read the torah; put the vowels between the consonants prds and you will get paradise: plain, symbolic, homiletic and esoteric Reading." (2007, p. 452). Podemos pensar que ao circular entre as línguas, como também o fazia o exilado e Heimatlos Vilém Flusser, ele esteja na busca dessa língua pura que apanharia de uma vez o mundo. A tradução é uma parte essencial da poesia de Amâncio. Em seu poema plurilíngue "Arestas Três", do volume Abrolhos (2007, p. 477-579), temos um exemplo de poema-tradução que é a inscrição e tradução em português, inglês e hebraico, como se uma língua ecoasse e completasse a outra.

É uma experiência única deixar-se levar por essa poética à deriva de Amâncio que se intensifica em seu último livro, o Matula. Os fragmentos de mundo que ela vai desenhando fazem-nos pensar que é da tristeza e do lamento que emana paradoxalmente tanta beleza. Como em uma elegia - mas deslocada pela ironia. A autoconsciência dessa ambiguidade surge em um pequeno poema: "interrompe e/ se torna/ fonte// água e chuva”. E essa chuva cai e nos molha, fecunda a terra, e novamente nos faz lembrar do esquecimento e que "o esquecimento", como escreveu Benjamin, "diz sempre respeito ao melhor, porque diz respeito à possibilidade da redenção”. (2012, p. 174). 
FORGETFULNESS IS RELATED TO THE BEST: MULTILINGUALISM AND

WANDERING IN THE POEMS OF MOACIR AMÂNCIO

\section{Abstract}

The text discusses the volume Matula, by Moacir Amâncio. There the poet collected the fragments of Iberian Jewishness and its developments in Amsterdam, Recife and around the world. The article shows how in this book everything is transformed into a memory trait. These marks are revaluated and constitute a work that in addition to memorial is deeply ironic, because it recycles in a free, open and often fun way, centuries of stories and narratives. The plurilingual universe of Amancio, who also writes in Hebrew, Spanish, and English, runs into Ladino, the language of Sephardic Jewry, corresponds to the dispersal of Jews persecuted by the Inquisition and always trying to survive in other lands. The Diaspora appears as a sequence of new meetings and losses.

KEYwORDS: Sephardic culture; wander; diaspora; plurilingual poetry.

EL OLVIDO SE RELACIONA AL MEJOR: PLURILINGUISMO Y ERRANCIA EN LOS poemas de MoACir AmÂnCIO

\section{RESUMEN}

El texto discute el volumen Matula, de Moacir Amáncio. El poeta recogió los fragmentos de la ibérica judía y de sus desdoblamientos en Ámsterdam, en Recife y en todo el mundo. El artículo muestra cómo en ese libro todo ahora se transforma en un rastro de memoria. Estas marcas son revalorizadas y constituyen una obra que además de memorial es profundamente irónica, pues recicla de modo libre, abierto y muchas veces divertido, siglos de historias y narrativas. El universo plurilingüe de Amáncio, que escribe también en hebreo, español, inglés y tropieza en el ladino, lengua de los judíos sefarditas, corresponde al periplo de la dispersión de los judíos, perseguidos por la Inquisición y siempre tratando de sobrevivir en otras tierras. La diáspora figura ahí como una secuencia de nuevos encuentros y de desencuentros.

PAlabras Clave: cultura sefardita; errante; diáspora; poesía plurilíngue. 
REFERÊNCIAS

ABRAHAM, N.; TOROK, M. A casca e o núcleo. Tradução Maria José Coracini. São Paulo: Escuta, 1995.

AMÂNCIO, Moacir. Ata. Rio de Janeiro: Record, 2007.

. Matula. São Paulo: AnnaBlume, 2016.

BENJAMIN, Walter. Franz Kafka: a propósito do décimo aniversário da sua morte. In: - Magia e técnica, arte e política: ensaios sobre literatura e história da cultura. Tradução S. P. Rouanet. Revisão técnica M. Seligmann-Silva. São Paulo: Brasiliense, 2012. p. 147-178.

. Ursprung des deutschen Truerspiels. In: . Gesammelte Frankfurt a.M.: Suhrkamp, 1980. p. 203-430. (v. I).

. Über die Spache überhaupt und über die Sprache des Menschen. In: . Gesammelte Schriften. Frankfurt a.M.: Suhrkamp, 1980. p. 140-157. (v. II).

BENJAMIN, Walter; SCHOLEM, Gershom. Correspondência. Tradução N. Soliz, São Paulo: Perspectiva, 1993.

CAMPOS, Haroldo de. Deus e o Diabo no Fausto de Goethe. São Paulo: Perspectiva, 1981.

. Hegel Poeta. In: . O arco-íris branco: ensaios de literatura e cultura. Rio de Janeiro: Imago, 1997. p. 61-73.

HARTHERLY, Ana. Experimentos visuais do barroco português. Os prodígios da língua. 1999. Disponível em: <http://www.jayrus.art.br/Apostilas/ LiteraturaPortuguesa/Barroco/Experimentos_Visuais_do_Barroco_ Portugues.htm>. Acesso em: 18 ago. 2017.

SCHOLEM, Gershom. Sabbatai Sevi: the Mystical Messiah, 1626-1676. Princeton, Nova Jersey: Princeton University Press, 1976.

Submetido em 11 de novembro de 2018

Aceito em 21 de novembro de 2018

Publicado em 25 de janeiro de 2019 